\title{
Orthotophic Liver Transplantation in Giant Hepatic Hemangioma: A Case Report and Literature Review
}

\author{
Jessica Casella ${ }^{1}$, Carla Lemos Gottgroy ${ }^{1}$, Carlos Rocha Maia ${ }^{2}$, Felipe Pedreira Tavares de Mello², \\ Samanta Teixeira Basto ${ }^{1}$, Claudia Cristina Tavares de Souza ${ }^{1}$, Eduardo de Souza Martins Fernandes ${ }^{2}$ \\ ${ }^{1}$ Hepatology, Liver transplant Unit, Adventist Silvestre Hospital, Rio de Janeiro, Brazil \\ ${ }^{2}$ Internal Surgery, Liver transplant Unit, Adventist Silvestre Hospital, Rio de Janeiro, Brazil \\ Email: stbasto@yahoo.com.br
}

Received February 28, 2013; revised March 2, 2013; accepted April 5, 2013

Copyright (C) 2013 Jessica Casella et al. This is an open access article distributed under the Creative Commons Attribution License, which permits unrestricted use, distribution, and reproduction in any medium, provided the original work is properly cited.

\begin{abstract}
Hemangioma is the most common benign tumor affecting the liver in $7 \%$ of general population. One of the rare presentations of this pathology is gigantic liver hemangioma, reported in the literature as anecdotal cases. In selected cases, liver transplantation has been a therapeutic option. We herein describe a case of massive liver hemangioma which was submitted to liver transplant, and the main indication for liver transplant in this case was a severe psychosocial impact of the disease in the patient's life, altogether with Kasabach-Merritt syndrome and abdominal discomfort.
\end{abstract}

Keywords: Liver Hemangioma; Liver Transplantation

\section{Introduction}

Hemangioma is the most common benign tumor affecting the liver in $7 \%$ of general population [1,2]. Clinical evolution is mainly asymptomatic and most identified cases are discovered in routine imaging test, deserving only sometimes a regular follow up [3]. In extremely exceptional cases, hepatic hemangioma may cause complications such as abdominal discomfort, Kasabach-Merritt syndrome, rupture, malignancy or internal abdominal bleeding [4-8].

One of the rare presentations of this pathology is gigantic liver hemangioma, reported in the literature as anecdotal cases. The lesion may occupy the whole liver parenchyma, without loss of its function, though. The liver may reach such massive volumes, causing abdominal compartment syndrome, so that in certain cases, liver transplantation has been described as the only therapeutic choice [8-11].

We herein describe a case of massive liver hemangioma which was submitted to liver transplant, and the main indication for liver transplant in this case was a severe psychosocial impact of the disease in the patient's life, altogether with Kasabach-Merritt syndrome and abdominal discomfort.

\section{Case Report}

The patient was a 47-year-old female, born in Rio de Ja- neiro, Brazil. In 2004, during a twin pregnancy prenatal care, she had an abdominal ultrasound showing an intra hepatic 12-centimeter hiperechogenic image, suggestive of liver hemangioma. She was then referred for follow up by the local gastroenterologist. In following year, the patient had an abdomen CT-scan, showing the lesion progressing to 14 centimetres, plus compressive effect over structures of the liver hilum, the pyloric antrum region and pancreas, also compressing downward the right kidney and causing jejunum loop displacement. Later, an MR showed a voluminous lesion occupying almost the whole organ, sparing part of the VII and VI segments, with hypersignal on T2, light hyposignal on $\mathrm{T} 1$ and discontinued peripheral lobe impregnation pattern with centripetal progression, generating mass effect over adjacent structures. On spared segments there were various nodules with the same signs of primary lesion. At that time, she presented with mild asthenia and abdominal discomfort. The patient remained under medical surveillance for 7 years after the diagnosis, and was then referred to a liver transplant center. In her admission, she had a 96,000 plaquetary count and repeatedly episodes of bleeding gums, and was diagnosed as the Kasabach-Merritt syndrome (thrombocytopenia and consumptive coagulopathy in association with large hemangioma). She also referred a significant social inadequacy due to the volumenous abdominal increase, with impact on her marital 
status and work activities, leading to a major depressive disorder. She was started on antidepressant medication at this time, with partial response.

The patient was submitted to a deceased donor liver transplant after appreciation of the regional technical committee. An abdominal reoperation 24 hours after of surgery was performed due to hemoperitoneum, and the post operatory was uneventfully after that. Four months after the transplant the patient she had retook her social and working activities, with total remission of the general symptoms and the depression disorder, also retrieving antidepressant medication (Figure 1).

\section{Discussion}

Liver transplantation has been reported in the literature in rare selected cases of massive hepatic hemangiomatosis. According to a recent review, only 12 cases have been reported until now [12]. The indications consist in Kasabach-Merritt syndrome, characterized by thrombocytopenia and consumptive coagulopathy in association with a large hemangioma, abdominal pain or severe symptoms with discomfort, due to stretching of Glisson's capsule, compression of local structures, intralesional

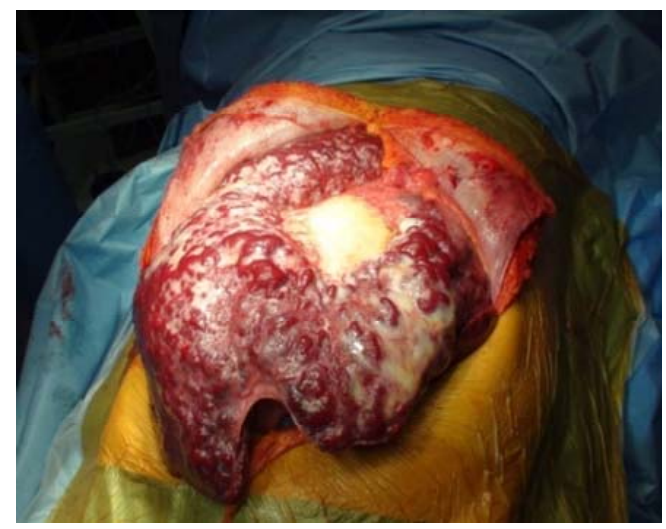

(a)

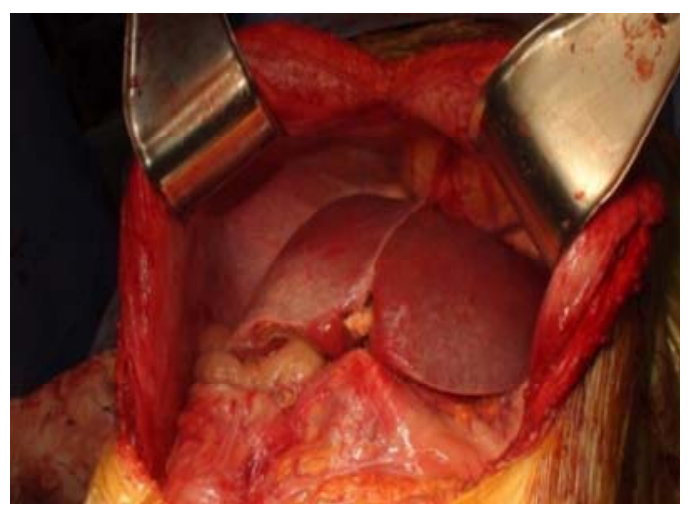

(b)

Figure 1. Liver transplantation intra operatory aspect: (a) Giant liver hemangioma and hepatomegaly; (b) Implanted liver deceased donor aspect. thrombosis and infarction, hemorrhage, spontaneous or traumatic rupture and in situations where is not possible to exclude malignancy, since biopsy is avoided because of its risks $[4,5,13]$.

The case describes a tipical patient: these lesions are more usually found in women (female/male ratio 5:1), with a mean age at diagnosis of 50 years $[14,15]$.

The patient had the Kasabach-Merritt syndrome, with worsening evolutionary thrombocytopenia, size increasing lesion through seven years, causing persistent abdominal symptoms and, markedly, psychosocial commitment. The situation led to the abandon of her labor and social activities, marital rupture and the diagnosis of major depression. Altogether, this situation corroborated for the decision of an invasive therapeutic modality as the liver transplantation. Thereby, after a careful assessment of risks and benefits of intervention were made, the evaluation of the regional technical committee and family written consent, a liver orthotopic transplantation was performed.

The long-term results of this intervention are quite satisfying. The overall 1-, 3- and 5-year survival rates were $84.9 \%, 81.2 \%$ and $75.9 \%$, respectively [11]. Today, surgery is the most effective therapeutic modality for the definitive treatment of selective cases of giant irresectable liver hemangioma and other benign tumors of the liver $[16,17]$. The success and penetration of liver transplantation procedure throughout the world is such, that a constant refinement of indications for transplantation in order to achieve a maximum utilization of a resource as precious and scarce as the liver graft is needed.

This article reports an uncommon presentation of a common disease, and a peculiar indication for liver transplant with a favorable outcome after surgery. The indication of liver transplantation in this case took into account not only the usual indications for hepatic giant irresectable hemangioma, but also, the overall context of the patient, i.e., clinical and psychosocial.

In conclusion, orthotopic liver transplantation for the treatment of giant hepatic hemangioma, despite being a definitive and curative therapy is a very rare indication; however, remains a viable option for a highly selected group of patients.

\section{REFERENCES}

[1] Y. G. Adam, et al., "Giant Hemangiomas of the Liver," Annals of Surgery, Vol. 172, 1970, pp. 239-245.

[2] P. Bioulac-Sage, H. Laumonier, C. Laurent, J. F.Blanc and C. Balabaud "Benign and Malignant Vascular Tumors of the Liver in Adults," Seminars in Liver Disease, Vol. 28, No. 3, 2008, pp. 302-314.

doi:10.1055/s-0028-1085098

[3] A. Cappellani, A. Zanghì, M. Di Vita, G. Zanghì, G. 
Tomarchio and G. Petrillo, "Spontaneous Rupture of a Giant Hemangioma of the Liver," Annali Italiani di Chirurgia, Vol. 71, No. 3, 2000, pp. 379-383.

[4] ELTR database. December de 2008. http://www.unos.org/donation/index.php?topic=unos_upd ate

[5] O. Farges, S. Daradkeh and H. Bismuth, "Cavernous Hemangiomas of The Liver: Are There Any Indications for Ressection?” World Journal of Surgery, Vol. 19, No. 1, 1995, pp. 19-24. doi:10.1007/BF00316974

[6] Ferraz A, S. F., et al, "Liver Transplant for the Treatment of Giant Hepatic Hemangioma,” Liver Transplantation, Vo. 10, No. 11, 2004, pp. 1436-1437. doi:10.1002/lt.20250

[7] Gilon D, P. E. Slater and J. Benbassat, "Can Decision Analayis Help in the Manegement of Giant Hemangioma of the Liver?” Journal of Clinical Gastroenterology, Vol. 13, No. 3, 1991, pp. 255-258.

[8] G. W. Hall, "Kasabach-Merrit Syndrome: Pathogenesis and Management," British Journal of Haematology, Vol. 112, No. 4, 2001, pp. 851-862. doi:10.1046/j.1365-2141.2001.02453.x

[9] S. N. Hochwald and L. H. Blumgart, "Giant Hepatic Hemangiomas with Kasabach-Merritt Syndrom: Is the Appropriate Treatment Enucleation or Liver Transplantation?” HPB Surgery, Vol. 11, No. 6, 2000, pp. 413-419. doi:10.1155/2000/25954

[10] M. Hotokezaka, M. Kojima, K. Nakamura, H. Hidaka, Y. Nakano, M. Tsuneyoshi and M. Jimi, "Traumatic Rupture of Hepatic Hemangioma," Journal of Clinical Gastroenterology, Vol. 23, No. 1, 1996, pp. 69-71. doi:10.1097/00004836-199607000-00020
[11] S. M. Lerner, J. R. Hiatt, J. Salamandra, P. W. Chen, D. G. Farmer, R. M. Ghobrial and R. W. Busuttil, "Giant Cavernous Liver Hemangiomas: Effect of Operative Approach on Outcome," Archives of Surgery, Vol. 139, No. 8, 2004, pp. 818-821. doi:10.1001/archsurg.139.8.818

[12] J.-H. Longeville, P. De La M. Hall, P. Dolan, A. W. Holt, P. E. Lillie, J. A. R. Williams andR. T. A. Padbury, "Treatment of a Giant Hemangioma of the Liver with Kasabach-Merritt Syndrome by Orthotopic Liver Transplant a Casa Report,” HPB Surgery, Vol. 10, 1997, pp. 159-162.

[13] M. S. Duxbury and O. J. Garden, "Giant Haemangioma of the Liver Observation or Resection?” Digestive Surgery, Vol. 27, No. 1, 2010, pp. 7-11. doi:10.1159/000268108

[14] B. Pol, P. Disdier, Y. P. Le Treut, P. Campan, J. Hardwigsen and P. J. Weiller, "Inflammatory Process Complicating Giant Hemangioma of the Liver: Report of Three Cases," Liver Transplantation and Surgery, Vol. 4, No. 3, 1998, pp. 204-207. doi:10.1002/lt.500040306

[15] S. I. Schawartz and W. C. Husser, "Cavernous Hemangioma of the Liver. A Single Institution Report of $16 \mathrm{Re}-$ sections," Annals of Surgery, Vol. 205, No. 5, 1985, pp. 456-465. doi:10.1097/00000658-198705000-00003

[16] J. H. Sewell and K. Weiss, "Spontaneous Rupture of Hemangioma of the Liver. A Review of the Literature and Presentation of Illustrative Case,” JAMA Surgery, Vol. 83, No. 5, 1961, pp. 729-733.

[17] UNOS database, based on OPTN data. May 2009 http://www.eltr.org/spip.php?spip0. 